\title{
Coding of movement direction and amplitude in Parkinson's disease: are they differentially impaired (or unimportant)?
}

\author{
Dean L Jones, James G Phillips, John L Bradshaw, Robert Iansek, Judy A Bradshaw
}

\begin{abstract}
A recent study suggested that the preparation of movement direction, but not amplitude, may be selectively impaired by Parkinson's disease (PD). The authors examined the reprogramming of direction only, amplitude only, and direction and amplitude together, and included a control condition in which neither parameter was reprogrammed. The findings suggested that neither direction nor amplitude coding was differentially impaired in PD. Thus the structures affected by PD may not be uniquely involved in specifying only the direction or the amplitude of future movements; these structures probably have more complex higher-level roles.
\end{abstract}

(F Neurol Neurosurg Psychiatry 1993;56:419-422)

Two reaction time (RT) studies by Pullman et al $^{12}$ suggest that Parkinson's disease (PD) may cause particular difficulty in the specification of the direction rather than the amplitude, of future movements. The same patients and procedures were used, measures were included of circulating plasma levodopa (the precursor to dopamine), and direction and amplitude were separately and independently varied in the two studies. The authors suggest that the preparation of movement direction, but not of amplitude, may be related to dopamine status. Unfortunately they failed to include two other conditions, where neither, or both, parameters were precued. While this requirement was largely met by Stelmach et al, ${ }^{3}$ whose findings suggested normal specification of both parameters, there was no complete group analysis in this study. There is some evidence that PD may cause difficulty in specifying movement amplitude. Thus large amplitude movements in PD fall short of target, ${ }^{4}$ and are associated with abnormally short initial EMG bursts in agonists, ${ }^{5}$ (see Berardelli et $a l^{6}$ ) A final reason for questioning the findings of Pullman et $a l^{12}$ comes from recent studies of cell activity in the basal ganglia, which have emphasised that such responses may not be related in any simple fashion to movement parameters. ${ }^{78}$

We therefore compared the programming of direction and amplitude parameters on their own and together, and when neither was prespecified. The task involved reprogramming an ongoing movement. ${ }^{9}$ Compared with the methods of Pullman et $a l^{12}$ and Stelmach et $a l^{3}$ this paradigm allows us to examine both the preparation of a new response and the inhibition of the current motor programme. Additionally, the above conditions (either, both, or neither parameter prespecified) can be achieved without confounding the number of stimuli related to each response. In the RT studies described above, ${ }^{1-3}$ some conditions involved just one visual cue, while others required two or more cues. This is an important issue, since PD may be associated with impaired maintenance of visual attention ${ }^{10}$ and poor control of eye movements. ${ }^{11}$ The present reprogramming design associates the same visual stimulus with all four task conditions.

\section{Method}

Subjects

Ten male PD subjects and 10 male control subjects participated voluntarily. All were right handed, and were screened for evidence of dementia, using the Mini-Mental State Examination (MMSE), ${ }^{12}$ other neurological impairments and use of neuroleptic medication. Clinical data for the PD subjects are shown in the table, including ratings of symptom severity ${ }^{13}$ and disease progression. ${ }^{14}$

The PD group had a mean age of 66.6 years, a mean premorbid IQ of 113 according to the New Adult Reading Test, NART, ${ }^{15}$ and a mean educational level of 11.1 years. The control group had a mean age of $65 \cdot 7$ years, a mean premorbid IQ of 116 , and a mean educational level of 10.2 years. According to one-way analyses of variance

\section{Clinical data for PD subjects}

\begin{tabular}{llcll}
\hline Number & Age & $\begin{array}{l}\text { Webster } \\
\text { ratings }\end{array}$ & $\begin{array}{l}\text { Hoehn } \\
\text { and Yahr }\end{array}$ & $\begin{array}{l}\text { Levodopa } \\
\left.\text { (mg day }{ }^{-1}\right)\end{array}$ \\
\hline 1 & 62 & 18 & III & 700 \\
2 & 78 & 14 & II & 400 \\
3 & 76 & 6 & II & 300 \\
4 & 70 & 14 & II & 650 \\
5 & 66 & 9 & II & 375 \\
6 & 64 & 10 & III & 500 \\
7 & 68 & 6 & II & 400 \\
8 & 64 & 5 & I (R) & 900 \\
9 & 40 & 17 & II & 1850 \\
10 & 78 & 16 & II & 500 \\
\hline
\end{tabular}

aStage of PD according to Hoehn and Yahr't (L: Left/R: Right side most affected). 
Figure Mean Movement Time (MT) before change and on change in movement for all reprogramming conditions, for Parkinson's disease and control subjects. Standard error bars are included.
(ANOVAs), the groups did not significantly differ in age, $F(1,18)<1$; premorbid intelligence, $F(1,18)=1 \cdot 14, p>0 \cdot 25$; or years of education, $F(1,18)<1$.

\section{Apparatus and procedure}

Testing took place at the most severe point in a patient's symptom cycle, that is, shortly before the next medication was taken. Each subject made responses on a board with a row of five buttons (1-5). The subjects sat so that the row of buttons lay along their sagittal plane. Adjacent buttons were separated by 30 $\mathrm{mm}$ (centre to centre) and each button was $13 \mathrm{~mm}$ in diameter. The buttons required a distance of $7 \mathrm{~mm}$ and a minimum force of 60 $\mathrm{g}$ to be depressed. A computer recorded the time data.

The subjects completed trials, each of which consisted of a series of 12 button presses, with their right hand as quickly and as accurately as possible. The movements between buttons alternated between being proximal-to-distal and distal-to-proximal. Each next button to be depressed was illuminated by a small red light emitting diode (in the base of the button) when the present button was released. Only one button was illuminated at any one time. On a typical trial, the subject depressed the starting button (button number 3) to begin, which caused the adjacent button (for example, button 4) to be

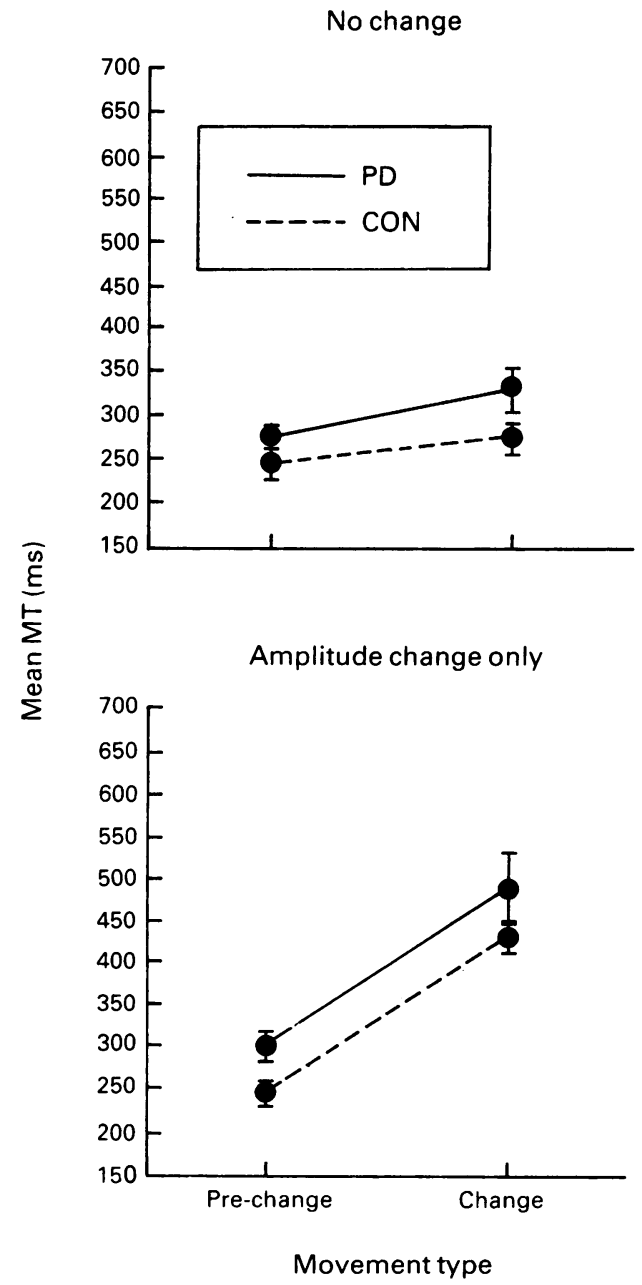

illuminated. After pressing that newly illuminated button, the original button (3) again lit up. In the no change condition, this back and forth movement (between buttons 3 and 4) continued for the entire trial of 12 button presses. However, under the other three conditions of cued change, a new button was illuminated on either the fifth, sixth or seventh movement. The new button could be: for example, A) twice the amplitude but in the same direction as the usual movement (for example, button 5, when the subject expected to go from 3 to 4 ); B) in the reverse direction but of the same amplitude as the usual movement (for example, button 2, when the subject again expected to go from 3 to 4), or C) both twice the amplitude and in the reverse direction (for example, now button 1). On depression of the new button, the next one illuminated returned subjects to the button from which they had previously departed (3), so that they could continue alternating as before, for the remaining movements in the trial. Thus where both direction and amplitude were changed on the fifth movement, an example trial was as follows: 3-4-3-4-3-1-3-4-3-4-3-4.

On half the trials the orientation of the board was reversed, so that the number of proximally and distally directed movements was the same for all conditions. There were 12 trials per condition, and the 4 conditions were presented in random order. The mea-

Direction change only

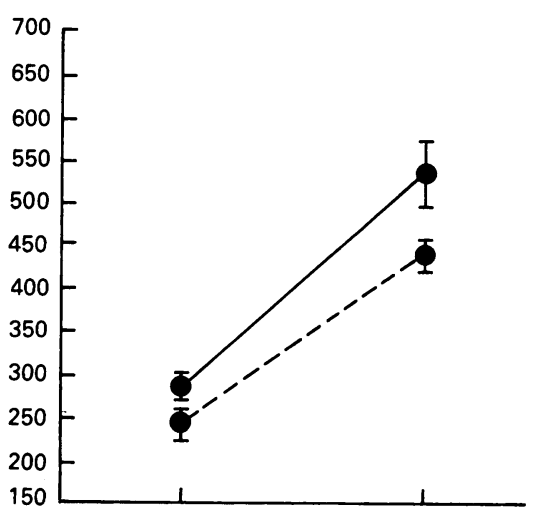

Direction and amplitude change

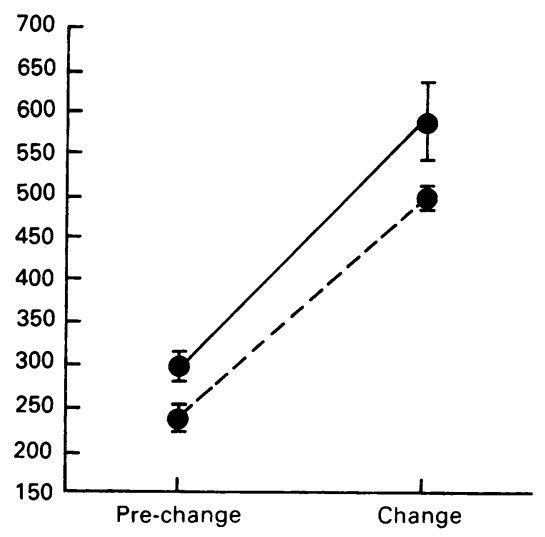

Movement type 
sures of interest for each trial were the movement time (MT) for the change movement, compared with the MT for the movement immediately before the change, that is, the pre-change movement from button 3 to button 4 . For trials with no change, a MT value was obtained for a movement in the sequence at the point corresponding to when a change would have occurred, had it been a change condition, that is, equiprobably at the fifth, sixth or seventh button tap.

\section{Results}

The extent of reprogramming is indicated by the increase in MT comparing pre-change and change conditions. To examine the extent of reprogramming we performed a mixed model $2 \times 4 \times 2$ analysis of variance considering Group (PD, control), Condition (no change, direction only change, amplitude only change, direction and amplitude change) and Movement Type (pre-change, change movement). A difficulty reprogramming specific movement parameters would be indicated by disproportionate increases in MT (pre-change vs change) for patients compared with controls. The MT for pre-change and change movements in all conditions is presented in the figure.

Significant main effects indicated that PD subjects moved slower (PD, $388 \mathrm{~ms}$ vs controls $327 \mathrm{~ms}), F(1,18)=6.51, p<0.05$; that reprogramming occurred (pre-change, 267 $\mathrm{ms}$ vs change $449 \mathrm{~ms}), \quad F(1,18)=129$, $p<0.001$; and that the specific conditions affected MT (no change, $281 \mathrm{~ms}$; direction only, $378 \mathrm{~ms}$; amplitude only, $366 \mathrm{~ms}$; direction and amplitude, $407 \mathrm{~ms}), F(3,54)=$ $66.04, p<0.001$. However, MT for each group was not differentially affected by the change in movement or by the condition, as indicated by non-significant interactions of Group by Condition $F(3,54)=1 \cdot 1, p>$ 0.05 ; and Group by Movement Type, $F(1$, $18)<1$. Note, from the figure, that both groups tend to slow down (that is, "fatigue") over time. There is, for instance, a slight increase in MT over the two positions even when no change of movement was required. Most importantly, however, this increase was not different for patients compared with controls, as shown by the lack of a significant interaction of Group by Condition by Movement Type, $F(3,54)<1$.

We can therefore conclude that PD and control subjects did not differ with respect to the effect on MT of the various changes in movement. PD subjects move slower, and can reprogramme their movements, but do not appear to have problems reprogramming any specific movement parameter.

\section{Discussion}

In this experiment, where a reprogramming technique was employed, PD subjects, while overall slower than controls, did not experience disproportionate difficulty in altering the direction and/or amplitude characteristics of ongoing movements. These results, while consistent with those of Stelmach et $a l^{3}$ in the RT paradigm, apparently conflict with those of Pullman et al. ${ }^{2}$ In our study hand movements were visually guided (permitting PD subjects to use preferred, external rather than internally generated cues), ${ }^{16}$ while in the studies of Pullman et al the entire arm was hidden from view. Use of such visual information, however, is unlikely to explain the present results, since Stelmach et $a l^{\beta}$ also used movements where the hands and arms were out of sight, and their results generally concurred with the present findings.

Our data and those of Stelmach et al suggest two possible explanations. Firstly, the basal ganglia may be involved in coding both direction and amplitude, a position which is compatible with certain data on cell activity in these structures. ${ }^{21}{ }^{22}$ Alternatively, the basal ganglia may not be primarily involved in specifying parameters of future movement, but may instead play some other role, probably at a higher level of motor function. This latter position has been taken by other, later, investigators of cell function in the basal ganglia. ${ }^{78}$ Clearly a broader view of basal ganglia function must be taken, to accommodate such complex concepts as motor programming, "internal" (or nonsensory) cueing, and sequential movement. According to this view, RT studies that demonstrate programming deficits in $\mathrm{PD}^{17-20}$ probably reflect problems in high level preparation processes, rather than problems in the simple specification of movement parameters. Note must be taken of the strong interconnections between the basal ganglia and the motor cortices. In particular, the supplementary motor area (SMA) probably participates in many higher motor functions, and is probably involved in motor programming and the dysfunction caused by PD. ${ }^{23}$

We very much appreciate the helpful comments of $\mathrm{Dr}$ Malcolm Horne on our findings. We also sincerely thank Dr David Andrewes and the Parkinson's Disease Association of Victoria for access to additional patients, and John Dick, Bob Wood, Mike Durham, Frank Devlin, and Truong Nguyen for designing and maintaining the apparatus and software. This work has been presented in part at a Meeting of the work has been presented in part at a Meeting of the
International Neuropsychological Society, Gold Coast, Australia, 1991.

1 Pullman SL, Watts RL, Juncos JL, Chase TN, Sanes JN. Dopaminergic effects on simple and choice reaction Dopaminergic effects on simple and choice reaction time performance

2 Pullman SL, Watts RL, Juncos JL, Sanes JN. Movement amplitude choice reaction time performance in Parkinson's disease may be independent of dopaminergic status. $f$ Neurol, Neurosurg, Psychiatry 1990;53:279-83.

3 Stelmach GE, Worringham CJ, Strand EA. Movement preparation in Parkinson's disease: The use of advance information. Brain 1986;109:1179-94.

4 Flowers K. Visual "closed-loop" and "open-loop" characteristics of voluntary movement in patients with Parkinsonism and intention tremor Brain 1976;99:269-310.

5 Hallett M, Khoshbin C. A physiological mechanism of bradykinesia. Brain 1980;103:301-14.

6 Berardelli A, Dick JPR, Rothwell JC, Day BL, Marsden CD Scaling of the first agonist EMG burst during rapid CD. Scaling of the first agonist EM burst during rapid wrist movements in patients with Parkinson's

Neurol, Neurosurg, Psychiatry 1986;49:1273-79. . parameters of movement. Brain 1991;114:1667-83. 
8 Brotchie P, Iansek R, Horne MK. Motor function of the monkey globus pallidus: II. Cognitive aspects of movement and phasic neuronal activity. Brain 1991;114:1685-702.

9 Larish DD, Frekany GA. Planning and preparing expected and unexpected movements: Reexamining the relationships of arm, direction and extent of movement. $¥$ Motor Behav 1985;1 17:168-89. 10 Wright MJ, Burns RJ, Geffen GM, Geffen LB. Covert oriimpairment in the maintenance of attention. Neuropsychologia 1990;28:151-9.

11 Crawford T, Goodrich S, Henderson L, Kennard C. Predictive responses in Parkinson's disease: Manual keypresses and saccadic eye movements to regular stimulus events. $\mathcal{f}$ Neurol, Neurosurg Psychiatry stimulus events.

12 Folstein MF, Folstein SE, McHugh PR. "Mini-mental state". A practical method for grading the cognitive state of patients for the clinician. $\mathcal{F}$ Psychiatric Res 1975;12:189-190.

13 Webster DD. Critical analysis of the disability in Parkinson's disease. Modern Treatment 1968;5:257-82.

14 Hoehn MM, Yahr MD. Parkinsonism: Onset, progression, and mortality. Neurology 1967;17:427-42.

15 Nelson HE, O'Connell A. Dementia: The estimation of premorbid/intelligence levels using the New Adult Reading Test. Cortex 1978;14:234-44.

16 Brown RG, Marsden CD. Internal vs external cues and the control of attention in PD. Brain 1988;111: 323-45.

17 Bloxham CA, Mindel TA, Frith CD. Initiation and execution of predictable and unpredictable movements in Parkinson's disease. Brain 1984;107:371-84

18 Evarts EV, Teräväinen H, Calne DB. Reaction time in Parkinson's disease. Brain 1981;104:167-86.

19 Goodrich S, Henderson L, Kennard C. On the existence of an attention demanding process peculiar to simple reaction time: Converging evidence from Parkinson's reaction time: Converging evidence from Parkinso
disease. Cognitive Neuropsychology 1989;6:309-31.

20 Sheridan MR, Flowers KA, Hurrell J. Programming and execution of movement in Parkinson's disease. Brain execution of movement in Parkinson's disease. Brain 21 Alexander GE, Crutch than joint coordinates of putamen and motor cortex preparatory activity preceding planned limb movements. In: Crossman AR, Sambrook MA, eds. Neural mechanisms in disorders of movement. London: John Libbey, 1989:55-62.

22 DeLong MR, Georgopoulos AP, Crutcher MD. Corticobasal ganglia relations and coding of motor performance. In: Massion J, Paillard J, Schurtz W, Weisendanger $\mathbf{M}$, eds. Neural coding of motor performance. Berlin: Springer-Verlag, 1983, 30-40.

23 Jones DL, Phillips JG, Bradshaw JL, Iansek R, Bradshaw JA. Impairment in bilateral alternating movements in Parkinson's disease? $f$ Neurol Neurosurg Psychiatry 1992;55:503-6. 